\title{
Sex Differences Independent of Other Psycho-sociodemographic Factors as a Predictor of Body Mass Index in Black South African Adults
}

\author{
Annamarie Kruger', Maria P. Wissing', Gordon W. Towers², and Colleen M. Doak \\ 'Africa Unit for Transdisciplinary Health Research and ${ }^{2}$ Centre of Excellence for Nutrition, \\ Faculty of Health Sciences, North-West University (Potchefstroom Campus), Potchefstroom, \\ South Africa, and ${ }^{3}$ Department of Health Sciences, Vrije Universiteit, Amsterdam, The Netherlands
}

\begin{abstract}
To better understand the sex differences in body mass index (BMI) observed in black South African adults in the Transition and Health during Urbanization of South Africans Study, the present study investigated whether these differences can be explained by the psycho-sociodemographic factors and/or health-related behaviours. A cross-sectional survey was undertaken among 1,842 black South African individuals from 37 study sites that represented five levels of urbanization. The behavioural factors that possibly could have an influence on the outcome of body-weight and that were explored included: diet, smoking, level of education, HIV infection, employment status, level of urbanization, intake of alcohol, physical activity, and neuroticism. The biological factors explored were age and sex. The prevalence of underweight, normal weight, and overweight among men and women was separately determined. The means of the variables were compared by performing Student's $t$-test for normally-distributed variables and Mann-Whitney Utest for non-normally-distributed variables. The means for the underweight and overweight groups were tested for significant differences upon comparison with normal-weight individuals stratified separately for sex. The differences in prevalence were tested using chi-square tests $(\mathrm{p}<0.05)$. All the variables with a large number of missing values were tested for potential bias. The association between sex and underweight or overweight was tested using the Mantel-Haenszel method of odds ratio (OR) and calculation of 95\% confidence interval (CI), with statistical significance set at $\mathrm{p}<0.05$ level. Logistic regression was used for controlling for confounders and for testing for effect modification. Females were more likely to be overweight/ obese (crude $\mathrm{OR}=5.1$; CI 3.8-6.8). The association was attenuated but remained strong and significant even after controlling for the psycho-sociodemographic confounders. In this survey, the risk for overweight/ obesity was strongly related to sex and not to the psycho-sociodemographic external factors investigated. It is, thus, important to understand the molecular roots of sex- and gender-specific variability in distribution of BMI as this is central to the future development of treatment and prevention programmes against overweight/obesity.
\end{abstract}

Key words: Body mass index; Body-weight; Cross-sectional studies; Gender; Overweight; Obesity; Sex difference; South Africa

\section{INTRODUCTION}

The nutrition transition describes a pattern of dietary and activity changes often observed in countries experiencing economic growth $(1,2)$. This pat-

All correspondence should be addressed to: (Reprints not available from authors)

Dr. A. Kruger

Faculty of Health Sciences

North-West University (Potchefstroom Campus)

Private Bag X6001, Potchefstroom 2520

South Africa

Email: annamarie.kruger@nwu.ac.za

Fax: +27 (0)182992088 tern has been associated with the rising prevalence of overweight and obesity among urban populations, often co-existing with undernutrition (3-5). In South Africa, this clustering of undernutrition and overweight/obesity was first reported by Steyn et al. who determined a high prevalence of stunted children and overweight/obese women in the same low-income community (6). Later studies reported similar findings in countries experiencing rapid economic transition (7-9).

Studies in which the roles of various gender/sexspecific risk factors were explored in relation to the status of body-weight are rare, although a number 
of surveys in different countries indicate that there are gender/sex differences in weight status. The association of overweight and obesity specifically with women in the African context needs to be explained. Currently, it is not clear whether sex or gender differences, or both, play a role. To understand the sex/gender differences, proper clarification of these terms is needed. As used in recent literature, the concept 'sex differences' refers to those variables that are exclusively biological whereas the 'gender differences' refer to the socially-defined differences between men and women and by definition also include variables relating to possible interactions between the biological and the environmental factors (10). As this study will focus on the possible role played by the psycho-sociodemographic and behavioural variables (which may include interactions among biological and environmental variables), the concept of 'gender differences' is preferred in the discussion rather than 'sex differences'.

Results of a study in South Africa on black teenagers showed that girls were particularly more prone to overweight/obesity compared to boys (11). Similar results from Africa, the Middle East (12-15), and Mexico (16) have been reported. However, surveys in Brazil showed that the prevalence of overweight/ obesity in this country was similar for men and women. Results of studies, conducted during the 1990s, showed that, in China (17) and Malaysia (18), men, rather than women, had a greater prevalence of overweight/obesity. However, Kelly et al. showed a clear global pattern with women having a higher prevalence of overweight/obesity compared to men (19). Furthermore, Mendez et al. showed that overweight in females already exceeded underweight in most developing countries (20).

The sex differences in metabolic rate are well-documented, and studies have demonstrated the genderspecific differences in dietary intake, smoking, and physical activity (21). However, no studies have explored the role of behaviour in explaining differing risks for men and women relating to underweight and overweight. The Transition and Health during Urbanization of South Africans (THUSA) Study, which focuses on a community experiencing the nutrition transition, provides an ideal population for exploring this question. Kruger et al. reported a high prevalence of overweight/obesity among women in the THUSA study (22). Furthermore, several psycho-sociodemographic and behavioural variables, including facets, such as neuroticism, were included and found to be significantly different over levels of urbanization (23). Data from 37 nations indicated that women had higher levels of neuroticism (24). Costa et al. confirmed this finding in data from 26 cultures but they also noted that, contrary to the predictions from an evolutionary perspective, the magnitude of the gender differences varied across cultures and that, contrary to a social role perspective, the gender differences were surprisingly greater in European and American samples in which the traditional gender roles are minimized (25). Faith et al. determined in a British sample that an increase in body mass index (BMI) was significantly associated with neuroticism in women only (26). In a large prospective study on the association of psychosocial factors with health and disease, Brummett et al. confirmed that neuroticism was related to BMI in women only (27). They argued that neuroticism can be an endogenous causal factor of obesity but Chrisler and McCreary pointed out that neuroticism may also be a reaction to the social context with its pressure on women to be slim within which the neuroticism is expressed (28). In an African context, obesity has traditionally been viewed as a sign of prosperity and health, although it is currently more often a sign of a poverty-related poor diet $(29,30)$. It is still unknown what the interactions among gender, neuroticism, and BMI in an adult black African group will be.

Therefore, understanding the gender- and sexspecific underweight and overweight determinants and their interactions is a critical first step towards potentially resolving the dual burden of undernutrition and overweight/obesity.

\section{MATERIALS AND METHODS}

\section{Study subjects}

The THUSA study was a cross-sectional survey of 1,842 individuals from 37 study sites that represented five levels of urbanization. The original sample design, selection of participants, and ethical practices were previously published (23). Fifty subjects were included from each of the following agegroups: $15-<25,25-<35,35-<45,45-<55,55-<65$, and $\geq 65$ years.

Due to the complexities of comparing results based on BMI classifications of the older and younger groups, the youngest group $(15-<25$ years) $(16-23$, $31)$ and the eldest group $(\geq 65)$ were excluded. The remaining four age-groups comprised the study subjects, with 1,325 individuals aged 25-64 years.

\section{Procedure}

The results found from male and female adults were compared in a descriptive manner to determine if the statistically significant determinants for obesity in females were the same in males and vice-versa.

The biological determinants investigated were age and sex while the behavioural determinants were 
diet, dependants sharing food, employment status, smoking, education, HIV infection, intake of alcohol, level of neuroticism, and physical activity. All measurements in the THUSA study were done using the appropriate validation and quality-control procedures and have been previously published (23).

\section{Exposure}

Weight status: Anthropometric measurements were taken by postgraduate students under the supervision of a level III anthropometrist. The weight status in this investigation was measured according to the BMI categories of the World Health Organization (WHO) for underweight, normal weight, and overweight/obesity. The WHO cut-off values for adults are defined as a BMI of $<18.5 \mathrm{~kg} / \mathrm{m}^{2}$ for underweight, $18.5-<25 \mathrm{~kg} / \mathrm{m}^{2}$ for normal weight, and $25 \mathrm{~kg} / \mathrm{m}^{2}$ and above for classifying overweight and obesity together.

\section{Determinants investigated}

Diet: The differences in the mean intake of total fibre, intake of total fruit and vegetable, energy, and percentage of energy from protein, carbohydrate, and fat between men and women were determined using the dietary intakes (including alcohol) as collected from a culturally-sensitive quantified foodfrequency questionnaire (QFFQ), which was developed and validated by MacIntyre et al. $(32,33)$. The respondents estimated portion-sizes using a food portion photograph book developed and tested for use in the African population of the North West province of South Africa (34). Portion-sizes were reported in household measures and were converted to weights using standard tables. The food intake was coded using the new food codes of the South African food-composition database of the South African Medical Research Council and was expressed as average amounts consumed per day (23).

Smoking: Smoking was expected to be associated with body-weight (35). Therefore, the gender differences in smoking were compared. The respondents were asked whether they currently smoke. The gender differences were compared according to category of smoking and using logistic models. Possible confounding due to smoking status was tested in association with underweight or overweight.

Education: Level of education was also a possible factor associated with body-weight status and was compared between men and women. Three levels of educational status were determined as follows: (a) no education; (b) lower than 10th grade; and (c) 10th grade and above.

HIV status: HIV is associated with underweight, and therefore, HIV infection may differ between men and women. The status of HIV was, thus, tested as a possible confounder. The status of HIV was determined using a 'rapid test' enzyme-immunological method (EnzymunTest®, anti-HIV 1+2+subtype $\Phi$, Boehringer Mannheim, Mannheim, Germany) (23).

Age: The study subjects within the age-categories of $15-<25,25-<35,35-<45,45-<55,55-<65$, and $\geq 65$ years were included. As the study design for THUSA already accounts for age by stratum, comparisons between strata were adjusted for age. Given the sampling design, age was not controlled for in the analysis as a confounder. However, the possible interactions between age and gender were explored.

Employment: The study subjects were asked to identify themselves as having a job or not. This was used as a dichotomous variable called 'job at moment'. The possible confounding interactions were determined by exploring whether results from the level of urbanization differed between men and women for those who were unemployed compared to those who had a job at the time of the study.

Level of urbanization: The level of urbanization was indicated according to the following five strata: (i) those living in commercial farms, (ii) under tribal law (rural), (iii) in an urban informal housing sector, (iv) in an urban established housing area, or (v) in an upper income urban neighbourhood. This analysis compared the prevalence of underweight and overweight individuals by sex for each level of urbanization. A linear relationship between the body-weight outcomes and the urbanization levels was not expected because of the socioeconomic differences within each of these environments. Therefore, each stratum was analyzed separately, and the reference group chosen was based on the most extreme differences.

Alcohol intake: Consumption of alcohol was categorized as high, moderate, and low based on the upper and lower limits of the current guidelines for the intake of moderate alcohol (36). This information was used for creating a per-diem recommendation. An intake of $\geq 30 \mathrm{~g}$ of alcohol by men was, thus, used as a cut-off for the high intake group compared to those who consumed less than $30 \mathrm{~g}$. The cut-off limit for women was $15 \mathrm{~g}$ for the high intake group compared to those who consumed $<15 \mathrm{~g}$. A high intake of alcohol, i.e. above the level recommended as moderate, was used for determining any associations between the intake of alcohol and underweight or overweight.

Physical activity: Levels of physical activity were based on the physical activity index developed and validated for use in this specific population (37). An 
index with a value from 1 to 3.3 was taken as low physical activity, an index with a value from 3.34 to 6.67 as moderate physical activity, and an index with a value higher than 6.67 as high physical activity (22). The cut-off value used for physical activity in this investigation was set at 2.5. This value was equivalent to the median for men and the 75th percentile for women. This allowed the maximization of comparability between men and women while still having sufficient samples in the analyses. Men and women with activity levels of above 2.5 were categorized as having high activity.

Having a child younger than 11 years at home: This variable was used for giving an indication of the presence of dependants who share a meal without any contribution. This influenced the portionsizes of the remaining family members, especially the caregivers of those children.

Neuroticism: Neuroticism was measured by the Setswana-validated neuroticism subscale $(\mathrm{N})$ of the revised NEO personality inventory (NEO-PI-R) of Costa and McCrae (38). $\mathrm{N}$ is an index of negative effects as manifested in fear, sadness, embarrassment, anger, guilt, and disgust. People with high scores on $\mathrm{N}$ cope more poorly than others with stress. A Cronbach's alpha reliability index of 0.86 was obtained. To test for stress as an explanation of the associations determined, all odds ratios (ORs) were tested for confounding using the highest tertile of the neuroticism index.

\section{Statistical methods}

The first analysis undertaken was to determine the prevalence of underweight, normal weight, and overweight among men and women separately. Simultaneously, the association between gender and underweight or overweight was tested using the Mantel-Haenszel method of OR and calculation of 95\% CI, with statistical significance set at the $\mathrm{p}<0.05$ level. Results of preliminary analysis indicated that all the variables, except the percentage of energy intake from fat, protein, and carbohydrate, were not normally distributed. The mean comparisons of the non-normally-distributed variables were obtained using the Mann-Whitney test. A preliminary exploration of all the variables was undertaken based on the mean differences for the continuous variables. The means for underweight and overweight groups were tested for significant differences upon comparison with normal-weight individuals. For dichotomous comparisons, the chi-square test was used. All the initial statistical comparisons were used for testing the differences among the overweight, underweight and normalweight groups stratified separately by sex. The differences in prevalence were tested using the chi-square test $(\mathrm{p}<0.05)$.
All the variables with a large number of missing values were explored for potential bias. Bias was assessed by comparing the results for the study subjects with and without the values missing for a given variable.

Sets of questionnaire to determine the level of physical activity and neuroticism were completed for only a sub-sample of the participants in the THUSA study. It was determined that the sample was biased due to the fact that these variables were collected mostly in urban areas. To avoid introducing the possible bias by controlling for a variable that was collected on a sub-sample that differed from the total population, the models used in this investigation were not controlled for physical activity and neuroticism.

Based on a $10 \%$ change in the OR, there was no confounding effect determined for the intake of fibre, consumption of alcohol, education, status of HIV, age-group, having a child younger than 11 years at home, and the urbanization level of an individual. The smoking status did not confound the association between female sex and overweight/ obesity but did partially explain the association between gender and underweight. The protective association between female sex and underweight was attenuated and was no longer significant after controlling for the smoking status $(\mathrm{OR}=0.67$; CI 0.44-1.02). For this reason, smoking was controlled for in further analyses.

\section{Ethical approval}

The Ethics Committee of the former Potchefstroom University for Christian Higher Education approved the study, and all participants gave written informed consent.

\section{RESULTS}

Figure 1 presents the stacked prevalence of underweight, normal weight, overweight, and obesity for men and women included in the study. These results indicate a higher prevalence of underweight among males (20.2\%) and overweight/obesity among females (60.3\%).

Figure 2 depicts a clear and consistent sex pattern in which men had a high prevalence of underweight in all the strata of urbanization, except the upper-income urban areas whereas women had a higher prevalence of overweight in all the strata of urbanization. In the informal sector, $30.7 \%$ of the men were underweight while $55.1 \%$ of the women were either overweight or obese. In the total sample, only 22 males were categorized as obese.

The measured baseline characteristics that might influence the prevalence of obesity for men and 


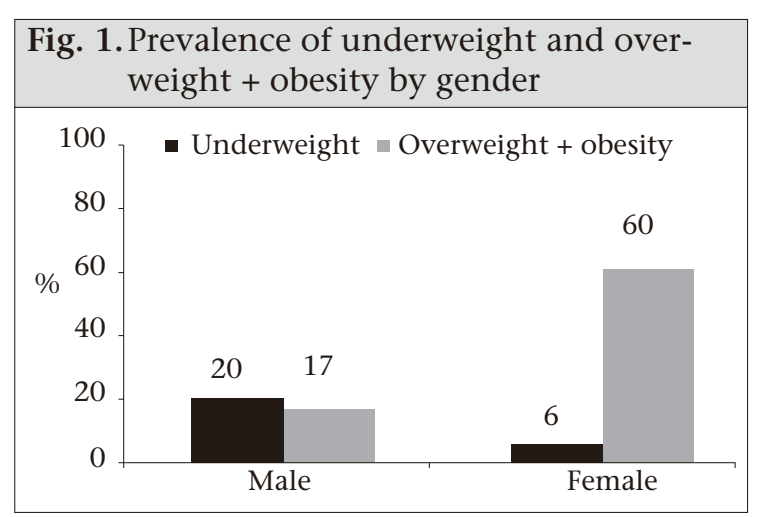

HIV in this population. Consistent with the study design, there were no differences between men and women when categorized according to age. Proportionately, more men were employed at the time of the study compared to women $(60.7 \%$ vs $42.1 \%, \mathrm{p}<0.001$ ) whereas more men had a high level of alcohol intake $(22.8 \%$ vs $6.9 \%, \mathrm{p}<0.001)$ and a higher activity level (66.4\% vs $41.6 \%$, $\mathrm{p}<0.001)$. Although only half of the study sample had values for the neuroticism index, the gender differences were significant. Proportionally, more females had scores for neurosis in the third and fourth quartiles $(\mathrm{p}=0.008)$ (Table 2).

Fig. 2. Prevalence of weight status by gender and stratum of urbanization

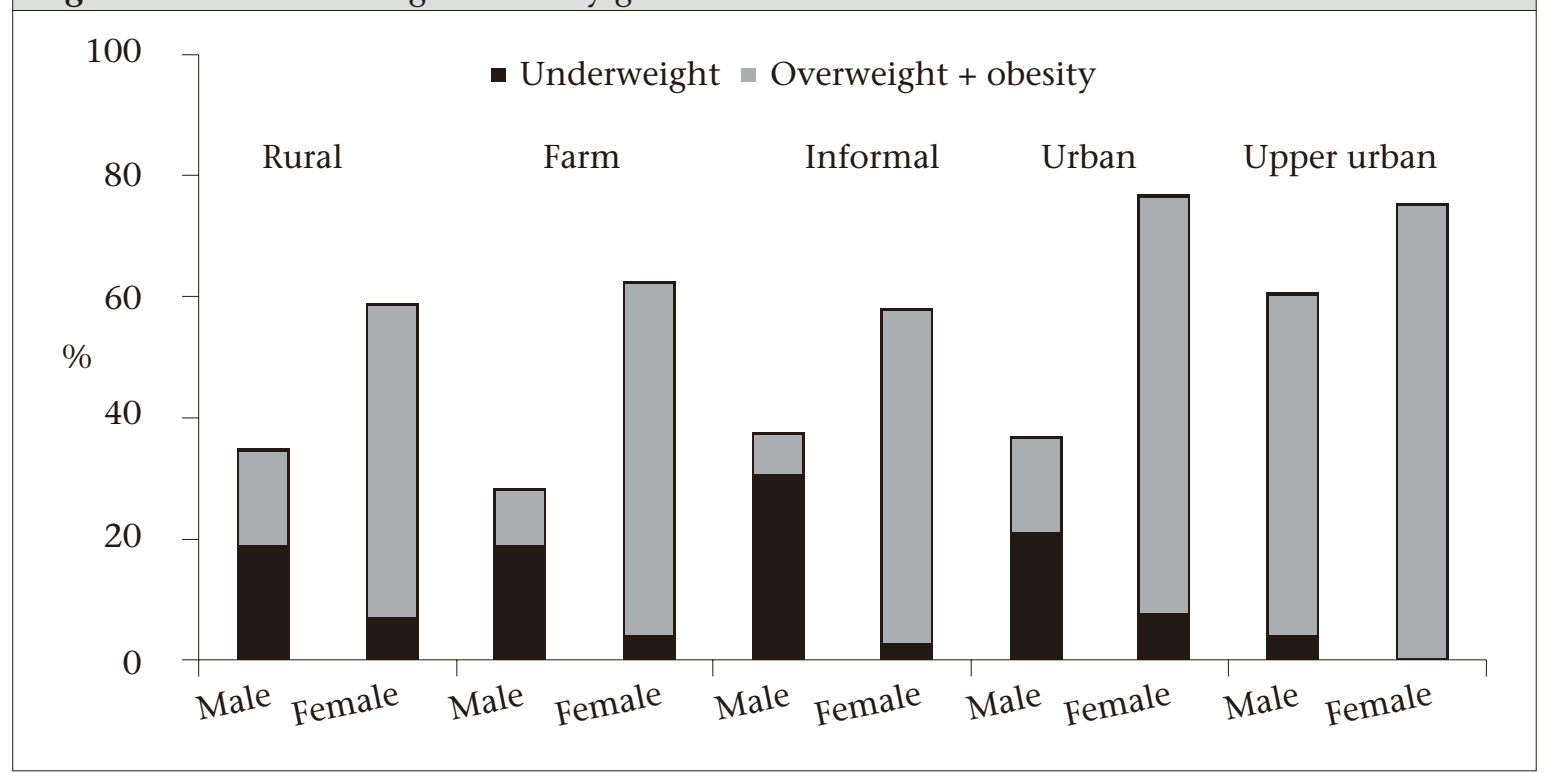

women are presented in Table 1 and 2 . The results indicate that women had a higher mean BMI [27.8 $\mathrm{kg} / \mathrm{m}^{2} \pm$ standard deviation (SD) of 7], a higher percentage of energy from the intake of fat $(25.6 \%$ $\mathrm{SD} \pm 7.3)$, and a higher mean neuroticism index (171.1 SD \pm 21.4$)$ than men $\left(21.5 \mathrm{~kg} / \mathrm{m}^{2} \mathrm{SD} \pm 4.1\right.$; 24.5\% SD \pm 7.6 ; and 167.3 $\mathrm{SD} \pm 21.6$ respectively). Men, however, had a significantly higher mean intake of fibre $(17.4 \mathrm{~g} /$ day $\mathrm{SD} \pm 8.9)$, total energy $(9,377.5 \mathrm{Kj} \mathrm{SD} \pm 3,884.8)$, a percentage of energy from alcohol (5.6 g/day $\mathrm{SD} \pm 8.3)$, and a higher mean physical activity score $(3.4 \mathrm{SD} \pm 1.6)$ than women (16 g/day SD $\pm 7.4 ; 7,818.7 \mathrm{Kj} \mathrm{SD} \pm 3,058.5 ; 1.2$ g/day $\mathrm{SD} \pm 3.7$; and 2.6 SD \pm 0.7 respectively) (Table 1 ).

The prevalence of current smokers was three times higher among men (65.5\% vs $20.1 \%)$ than among women. Furthermore, more men had no education $(\mathrm{p}=0.003)$ while women were more likely to have a middle level of education $(\mathrm{p}=0.012)$. No significant differences in the frequency of higher education ( $\mathrm{p}=0.902)$ were determined between men and women. Thirteen percent of the men and $11 \%$ of the women were identified as being infected with
The results for the stratum-specific ORs for females after controlling for smoking status are presented in Table 3. In all the strata, being female was strongly and significantly associated with overweight/ obesity. However, the ORs were not same within all the groups. The association between female sex and overweight/obesity was stronger if there was "no child younger than 11 years at home" compared to when there was a child aged 11 years in the home. In all the age-groups (except for the $45-<55$ years), obesity was 5.9 to 7.3 times stronger among females. Given the differences in the strength of the association across the levels of strata, 'hav ng a child younger than 11 years at home' and 'age 45-<55 years' were selected as the possible effect modifiers.

The second column of Table 3 presents the association between gender/sex and underweight, indicating a consistent protective association between female sex and underweight. However, the only statistically significant finding was the association between female sex and underweight $(\mathrm{OR}=0.44)$ in rural areas, farms, and the informal sector (CI 0.26- 


\begin{tabular}{|c|c|c|}
\hline Variable & $\begin{array}{c}\text { Men } \\
(\mathrm{n}=530) \\
\text { Mean (SD) }\end{array}$ & $\begin{array}{c}\text { Women } \\
(\mathrm{n}=795) \\
\text { Mean (SD) }\end{array}$ \\
\hline $\mathrm{BMI}^{*}\left(\mathrm{~kg} / \mathrm{m}^{2}\right)$ & $21.5(4.1)$ & $27.8(7.0)$ \\
\hline Fibre* $^{*}$ (g/day) & $17.4(8.9)$ & $16.0(7.4)$ \\
\hline Fruit and vegetable (g/day) & $2.1(1.8)$ & $2.4(2.2)$ \\
\hline Total energy*(kJ) & $9,377.5(3,884.8)$ & $7,818.7(3,058.5)$ \\
\hline$\%$ of food energy from protein & $12.1(2.1)$ & $11.9(2.3)$ \\
\hline$\%$ of food energy from fat ${ }^{\star *}$ & $24.5(7.6)$ & $25.6(7.3)$ \\
\hline$\%$ of food energy from carbohydrate & $65.1(9.9)$ & $64.1(9.9)$ \\
\hline$\%$ of energy from alcohol ${ }^{\star *}$ & $5.6(8.3)$ & $1.2(3.7)$ \\
\hline Physical activity index $($ Men=281 and women=387) & $3.4(1.6)$ & $2.6(0.7)$ \\
\hline Neuroticism index* men $n=246$ women $(n=328)$ & $167.3(21.6)$ & $171.1(21.4)$ \\
\hline
\end{tabular}

0.75). Alternatively, in the urban residents (including those residing in upper-income areas), female sex was positively associated $(\mathrm{OR}=1.97$; $\mathrm{CI} 0.92$ 4.22) with underweight, albeit non-significantly. Again, when the stratum-specific ORs were further controlled for physical activity and neuroticism, these results were amplified rather than diminished (data not indicated). Given these very different effects of sex in relation to underweight, 'urban residence' was selected as a possible effect modifier.

Table 4 explores the effect modification for variables selected based on the above analysis, thus 'having a child younger than 11 years at home', 'age of 45$<55$ years', and 'urban residence' were tested as the effect modifiers of the relationship of sex with BMI. The results were tested using a logistic model while controlling for the confounding effect of smoking status (current smoker). Using the criteria of $\alpha<0.10$ for the interaction term, the results indicate that female sex was associated with an increased risk of overweight/obesity in all the strata $(\mathrm{p}=0.05)$. The interaction term shows that 'having a child younger than 11 years at home' was an effect modifier $(\mathrm{p}=0.02)$. As indicated in Table 3 and confirmed in Table 4, "having a child younger than 11 years at home" had a strong association between female sex and overweight/obesity. All the analyses were repeated controlling for both physical activity and the upper tertile of the neuroticism index (NEO-PI-R). The results indicate the same significant interactions (data not shown).

\section{DISCUSSION}

We tested the possible behavioural, biological and sociodemographic determinants of BMI in men and women separately and then compared the results to understand the weight differences between the study men and women.
The results indicate that, in all the strata, female sex was strongly and significantly associated with overweight/obesity even after controlling for the available behavioural confounders. However, the results do indicate that the effect of female sex on overweight/obesity was modified, and is less strong, in homes where children were sharing meals without any contribution. In contrast, urban residence was determined to modify the effect of female sex on underweight. The females of the farms, rural areas, and the informal sector were less likely to be underweight, and the urban/upper urban females were more likely to be underweight.

Except for sex, no other variables investigated in the study were associated with an increased risk for overweight/obesity. This implies that overweight/ obesity may rather be due to an inherent susceptibility than to an external factor. The most prominent theories regarding obesity susceptibility state that the increased lipid storage capabilities may have been positively adaptive in populations undergoing numerous periods of famine, thus resulting in selection for the 'thrifty genotype' (39-41). The apparent increase in obesity/overweight observed in such populations is, therefore, merely the outcome of the interaction of this ancestral genotype with a food-rich environment (42) and insulin resistance (43).

The 'thrifty gene' hypothesis is one of the major hypotheses given for the global epidemic of obesity but it has come under fire in recent years due to lack of strong candidates for the 'thrifty gene' (44), and the increased evidence that the selective forces central to this hypothesis may not have been as strong as previously hypothesized (45). Furthermore, this hypothesis has been mainly applied to the European-descended populations, and its application to understanding the causes of increased 


\begin{tabular}{|c|c|c|}
\hline Variable & $\begin{array}{c}\text { Men } \\
(\mathrm{n}=530)\end{array}$ & $\begin{array}{l}\text { Women } \\
(\mathrm{n}=795)\end{array}$ \\
\hline Current smoker* & 65.5 & 20.1 \\
\hline \multicolumn{3}{|l|}{ Level of education } \\
\hline None $e^{* *}$ & 28.6 & 21.5 \\
\hline$\leq 10^{\text {th }} \operatorname{grade}^{\star *}$ & 32.8 & 39.6 \\
\hline $\begin{array}{l}10^{\text {th }} \text { grade and } \\
\text { above }\end{array}$ & 38.5 & 38.9 \\
\hline HIV infection status & 13.0 & 10.9 \\
\hline \multicolumn{3}{|l|}{ Age-group (years) } \\
\hline $25-<35$ & 34.5 & 35.1 \\
\hline $35-<45$ & 24.9 & 29.4 \\
\hline $45-<55$ & 24.3 & 22.5 \\
\hline $55-<65$ & 16.2 & 13.0 \\
\hline Employed ${ }^{*}$ & 60.7 & 42.1 \\
\hline \multicolumn{3}{|l|}{$\begin{array}{l}\text { Intake of alcohol } \\
\text { above the } \\
\text { recommended }\end{array}$} \\
\hline $\begin{array}{l}\text { Child aged }<11 \text { years } \\
\text { at home }\end{array}$ & 50.4 & 63.4 \\
\hline \multicolumn{3}{|l|}{ Urbanization level } \\
\hline $\begin{array}{l}\text { Rural (under tribal } \\
\text { law) }\end{array}$ & 25.7 & 30.4 \\
\hline $\begin{array}{l}\text { Commercial farm } \\
\text { areas }\end{array}$ & 16.8 & 15.7 \\
\hline $\begin{array}{l}\text { Informal } \\
\text { settlements } \\
\text { (squatter camps) }\end{array}$ & 16.6 & 16.6 \\
\hline $\begin{array}{l}\text { Urban (established } \\
\text { housing in } \\
\text { townships) }\end{array}$ & 31.9 & 28.1 \\
\hline $\begin{array}{l}\text { Upper urban } \\
\text { (main town areas) }\end{array}$ & 9.1 & 9.2 \\
\hline $\begin{array}{l}{ }^{*} \mathrm{p}<0.001 ;{ }^{* *} \mathrm{p}<0.05 ; \ddagger \mathrm{B} \\
\text { guidelines: men }>30 \mathrm{~g} \\
\text { day (31) }\end{array}$ & $\begin{array}{l}\text { d on } g \\
y \text { and }\end{array}$ & $\begin{array}{l}\text {-specific } \\
\mathrm{n}>15 \mathrm{~g} /\end{array}$ \\
\hline
\end{tabular}

obesity in the African populations may, thus, not be appropriate. This is highlighted in the current analysis due to the fact that the overweight/obese phenotype is mainly observed in females whereas the males present with normal to underweight phenotypes, although they have been exposed to similar selective forces, i.e. periods of famine.

Observations from the results of this study lead to the elucidation of the possible causes of sex differences in overweight/obesity by investigating sexspecific molecular pathways. The first evidence for the sex-specific molecular pathways being responsible for the effects observed in this study can be gleaned from the fact that the overweight/obesity risk in the female black South Africans was modified in households with a child aged less than 11 years. Besides, the fact that this was used as an indicator of sharing a meal with children in this study, it might also be an indicator of a process where major hormonal changes occur in the female participants as the majority were still in their reproductive age. Thus, it is plausible to assume that the changes in estrogen homeostasis that occur during this period will affect all the processes controlled by hormones, such as leptin. Leptin is an adipocytesecreted hormone (46), which acts as an indicator of the level of fat storage (47) and regulates satiety, appetite, and weight in humans via activation of the specific hypothalamic pathways $(48,49)$. The baseline expression of this hormone is higher in women than in men, and it has been determined that treatment of adipocytes with estradiol resulted in an increased leptin expression in women whereas a similar effect was not observed in men (50). Similarly, it was determined that the testosterone levels correlate inversely with the leptin levels in both elderly and young men (51). Thus, the major sex hormones, such as estrogens and testosterone, seem to be central to the regulation of leptin and, in turn, weight management.

Another possibility might be the association between the short allele of the serotonin transporter gene, which was determined to be an independent risk factor for obesity in a population of European ancestry (52), and high levels of anxiety. Neuroticism is a personality trait particularly associated with depressive and anxiety disorders. Results of a literature review by Verhagen indicate a strong relationship between gender and neuroticism and also that females scored higher than males on neuroticism indices (53). These gender differences could suggest differences in heritability between the sexes. However, research regarding gender differences in the action of the serotonin transporter gene is still inconsistent. From a behavioural genetics perspective, the findings may reflect a unique interaction among genes, gender, and the environment (54). Epigenetics propose that the environmental factors may lead to changes in expression of genes.

The black South African population belongs to the macrohaplogroup L, which is the ancestral population from which all human populations originated (55). Thus, this population is not only one of the most ancient but it also harbours the highest levels of genetic variation. Upon further investigation, it may, therefore, arise that the explanation for the disparity between the sexes in terms of BMI distribution in the black South African population may be a more complex and nuanced interplay of factors. 


\begin{tabular}{|c|c|c|c|c|}
\hline \multirow{2}{*}{ Variable } & \multicolumn{2}{|c|}{ Overweight/obesity } & \multicolumn{2}{|c|}{ Underweight } \\
\hline & OR & $95 \% \mathrm{CI}$ & OR & $95 \% \mathrm{CI}$ \\
\hline Full sample & 5.07 & $3.77-6.8$ & 0.67 & $0.44-1.02$ \\
\hline No education & 5.42 & $2.90-10.15$ & 0.63 & $0.31-1.29$ \\
\hline Some education & 5.15 & $3.65-7.26$ & 0.69 & $0.41-1.17$ \\
\hline Job at the moment & 5.04 & $3.38-7.50$ & 0.57 & $0.27-1.20$ \\
\hline No job at the moment & 6.84 & $4.14-11.30$ & 0.64 & 0.37-1.09 \\
\hline Urban and upper urban & 5.87 & $3.68-9.36$ & 1.97 & $0.92-4.22$ \\
\hline Farm, rural area, and informal sector & 6.10 & $4.00-9.31$ & 0.44 & $0.26-0.75$ \\
\hline Child aged $<11$ years at home & 3.67 & $2.51-5.36$ & 0.57 & $0.31-1.05$ \\
\hline No child aged $<11$ years at home & 7.80 & $4.79-12.70$ & 0.86 & $0.48-1.56$ \\
\hline \multicolumn{5}{|l|}{ Age-group (years) } \\
\hline $25-<35$ & 6.34 & $3.48-11.53$ & 0.66 & $0.32-1.38$ \\
\hline $35-<45$ & 5.94 & $3.33-10.61$ & 0.46 & $0.17-1.22$ \\
\hline $45-<55$ & 3.28 & $1.90-5.68$ & 0.79 & $0.36-1.72$ \\
\hline $55-<65$ & 7.26 & $3.27-6.12$ & 0.72 & $0.26-2.00$ \\
\hline
\end{tabular}

\begin{tabular}{|c|c|c|c|c|c|c|c|c|}
\hline & \multicolumn{4}{|c|}{$\begin{array}{l}\text { Modelling the association with } \\
\text { overweight/obesity }\end{array}$} & \multicolumn{4}{|c|}{$\begin{array}{l}\text { Modelling the association with } \\
\text { underweight }\end{array}$} \\
\hline \multicolumn{9}{|c|}{ Testing for interaction between female gender and having a child aged $<11$ years at home } \\
\hline & $\beta$ & $\mathrm{p}$ value & OR & $95 \% \mathrm{CI}$ & $\beta$ & p value & OR & $95 \% \mathrm{CI}$ \\
\hline Intercept & -1.27 & $<0.01$ & & & -0.44 & 0.33 & & \\
\hline Female gender $(=\operatorname{Var} 1)$ & 0.62 & 0.16 & 1.86 & $0.79,4.40$ & -0.91 & 0.16 & 0.40 & $0.11,1.43$ \\
\hline Current smoker (=Var 2) & 0.70 & $<0.01$ & 2.02 & $1.51,2.70$ & -0.79 & $<0.01$ & 0.45 & $0.30,0.69$ \\
\hline $\begin{array}{l}\text { Child }(<11 \text { years) in the } \\
\text { household (=Var } 3 \text { ) }\end{array}$ & -0.73 & $<0.01$ & 0.48 & $0.29,0.78$ & 0.21 & 0.35 & 1.23 & $0.79,1.92$ \\
\hline Interaction Var 1 * Var 3 & 0.70 & 0.02 & 2.01 & $1.12,3.62$ & 0.37 & 0.36 & 1.45 & $0.66,3.18$ \\
\hline \multicolumn{9}{|c|}{ Testing for interaction between female gender being aged $45-<55$ years } \\
\hline & $\beta$ & $\mathrm{p}$ value & OR & $95 \% \mathrm{CI}$ & $\beta$ & $\mathrm{p}$ value & OR & $95 \%$ CI \\
\hline Intercept & -1.10 & 0.51 & & & 0.03 & 0.75 & & \\
\hline Female gender (=Var 1$)$ & 0.71 & 0.57 & 2.04 & $0.67,6.25$ & -0.06 & 0.14 & 0.40 & $0.11,1.43$ \\
\hline Current smoker (=Var 2) & 0.72 & 0.15 & 2.06 & $1.53,2.77$ & -0.77 & $<0.01$ & 0.45 & $0.30,0.69$ \\
\hline Age $45-<55$ years $(=\operatorname{Var} 3)$ & -0.73 & 0.26 & 0.48 & $0.29,0.81$ & -0.10 & 0.72 & 1.23 & $0.79,1.92$ \\
\hline Interaction Var 1 * Var 3 & 0.54 & 0.32 & 1.71 & $0.91,3.22$ & -0.20 & 0.66 & 1.45 & $0.66,3.18$ \\
\hline \multicolumn{9}{|c|}{ Testing for interaction between female gender and urban residence } \\
\hline & $\beta$ & $\mathrm{p}$ value & OR & $95 \% \mathrm{CI}$ & $\beta$ & $\mathrm{p}$ value & OR & $95 \% \mathrm{CI}$ \\
\hline Intercept & -0.89 & 0.05 & & & -0.15 & 0.75 & & \\
\hline Female gender (=Var 1$)$ & 1.56 & $<0.01$ & 4.75 & $1.84,12.28$ & 1.05 & 0.15 & 2.85 & $0.69,11.69$ \\
\hline Current smoker (=Var 2) & 0.61 & $<0.01$ & 1.83 & $1.36,2.47$ & -0.85 & $<0.01$ & 0.43 & $0.28,0.65$ \\
\hline Urban residence (=Var 3) & -0.86 & $<0.01$ & 0.42 & $0.26,0.69$ & 0.07 & 0.78 & 1.07 & $0.67,1.69$ \\
\hline Interaction Var 1 * Var 3 & 0.14 & 0.65 & 1.15 & $0.64,2.06$ & -0.85 & .042 & 0.43 & $0.19,0.97$ \\
\hline
\end{tabular}

\section{Conclusions}

The findings of the present study highlight the importance of understanding the molecular roots of the sex/gender-specific variability in BMI distribu- tion in black South African adults. This process is central to the future development of treatment and prevention programmes against overweight/obesity in this population. 


\section{ACKNOWLEDGEMENTS}

The authors gratefully acknowledge the THUSA research team and the leader Prof. H.H. Vorster for making the data available.

\section{REFERENCES}

1. Popkin BM. Dynamics of the nutrition transition and its implications for the developing world. Forum Nutr 2003;56:262-4.

2. Popkin BM, Gordon-Larsen P. The nutrition transition: worldwide obesity dynamics and their determinants. Int J Obes Relat Metab Disord 2004;28(Suppl 3):S2-9.

3. Doak C, Adair L, Bentley M, Fengying Z, Popkin B. The underweight/overweight household: an exploration of household sociodemographic and dietary factors in China. Public Health Nutr 2002;5:215-21.

4. Doak CM, Adair LS, Bentley M, Monteiro C, Popkin $\mathrm{BM}$. The dual burden household and the nutrition transition paradox. Int J Obes (Lond) 2005;29:12936.

5. Garrett J, Ruel MT. The coexistence of child undernutrition and maternal overweight: prevalence, hypotheses, and programme and policy implications. Matern Child Nutr 2005;1:185-96.

6. Steyn K, Bourne L, Jooste P, Fourie JM, Rossouw K, Lombard C. Anthropometric profile of a black population of the Cape Peninsula in South Africa. East Afr Med J 1998;75:35-40.

7. Doak CM, Adair LS, Monteiro C, Popkin PM. Overweight and underweight coexist within households in Brazil, China and Russia. J Nutr 2000;130:2965-71.

8. Shafique S, Akhter N, Stallkamp G, de Pee S, Panagides D, Bloem MW. Trends of under- and overweight among rural and urban poor women indicate the double burden of malnutrition in Bangladesh. Int $J$ Epidemiol 2007;36:449-57.

9. Shukla HC, Gupta PC, Mehta HC, Hebert JR. Descriptive epidemiology of body mass index of an urban adult population in western India. J Epidemiol Community Health 2002;56:876-80.

10. Nobelius AM. When is it sex difference and when is it gender difference? Victoria: Monash University, 2004. (http://www.med.monash.edu.au/gendermed/ difference.html, accessed on 11 January 2011).

11. Jinabhai CC, Reddy P, Taylor M, Monyeki D, Kamabaran N, Omardien R et al. Sex differences in under and over nutrition among school-going Black teenagers in South Africa: an uneven nutrition trajectory. Trop Med Int Health 2007;12:944-52.

12. Mufunda J, Scott LJ, Chifamba J, Matenga J, Sparks $\mathrm{B}$, Cooper R et al. Correlates of blood pressure in an urban Zimbabwean population and comparison to other populations of African origin. J Hum Hypertens 2000;14:65-73.
13. Prentice AM. The emerging epidemic of obesity in developing countries. Int J Epidemiol 2006;35:93-9.

14. Doak CM, Popkin BM. The emerging problem of obesity in developing countries. In: Semba RD, Bloem MW, editors. Nutrition and health in developing countries. Totowa, NJ: Humana Press, 2001:447-64.

15. Doak CM, Popkin BM. The rapid emergence of obesity in developing countries. In: Semba RD, Bloem MW, editors. Nutrition and health in developing countries. 2nd ed. Totowa, NJ: Humana Press, 2008:617-38.

16. Rivera JA, Barquera S, Campirano F, Campos I, Safdie $\mathrm{M}$, Tovar V. Epidemiological and nutritional transition in Mexico: rapid increase of non-communicable chronic diseases and obesity. Public Health Nutr 2002;5(1A):113-22.

17. Ge K, Zhai F, Yan H. The dietary and nutritional status of Chinese population: 1992. National nutrition survey. Beijing: People's Medical Publishing House, 1996;1:1-40.

18. Ismail MN, Zawiah H, Chee SS, Ng KK. Prevalence of obesity and chronic energy deficiency (CED) in adult Malaysians. Mal J Nutr 1995;1:1-9.

19. Kelly T, Yang W, Chen CS, Reynolds K, He J. Global burden of obesity in 2005 and projections to 2030. Int J Obes (Lond) 2008;32:1431-7.

20. Mendez MA, Monteiro CA, Popkin BM. Overweight exceeds underweight among women in most developing countries. Am J Clin Nutr 2005;81:714-21.

21. Smith C, Essop MF. Gender differences in metabolic risk factor prevalence in a South African student population. Cardiovasc J Afr 2009;20:178-82.

22. Kruger HS, Venter CS, Vorster HH; THUSA Study. Physical inactivity as a risk factor for cardiovascular disease in communities undergoing rural to urban transition: the THUSA Study. Cardiovasc J S Afr 2003;14:16-23.

23. Vorster HH, Wissing MP, Venter CS, Kruger HS, Kruger A, Malan NT et al. The impact of urbanization on physical, physiological and mental health of Africans in the North West province of South Africa: the THUSA study. S Afr J Sci 2000;96:505-14.

24. Lynn R, Martin T. Gender differences in extraversion, neuroticism, and psychoticism in 37 nations. $J$ Soc Psychol 1997;137:369-73.

25. Costa PT, Jr., Terracciano A, McCrae RR. Gender differences in personality traits across cultures: robust and surprising findings. J Pers Soc Psychol 2001;81:322-31.

26. Faith MS, Flint J, Fairburn CG, Goodwin GM, Allison DB. Gender differences in the relationship between personality dimensions and relative body weight. Obes Res 2001;9:647-50.

27. Brummet BH, Babyak MA, Williams RB, Barefoot JC, Costa PT, Siegler IC. NEO personality domains and gender predict levels and trends in body mass index over 14 years during midlife. J Res Pers 2005;40:22236. 
28. Chrisler JC, McCreary DR. Handbook of gender research in psychology. New York, NY: Springer, 2010. $712 \mathrm{p}$.

29. Walker AR, Walker BF. High high-density-lipoprotein cholesterol in African children and adults in a population free of coronary heart disease. $\mathrm{Br} \mathrm{Med} \mathrm{J}$ 1978;2:1336-7.

30. Vorster HH, Kruger A, Venter CS, Margetts BM, Macintyre UE, THUSA Study. Cardiovascular disease risk factors and socio-economic position of Africans in transition: the THUSA Study. Cardiovasc J Afr 2007; 18:282-9.

31. da Veiga GV, da Cunha AS, Sichieri R. Trends in overweight among adolescents living in the poorest and richest regions of Brazil. Am J Public Health 2004;94:1544-8.

32. Maclntyre UE, Venter CS, Vorster HH. A culturesensitive quantitative food frequency questionnaire used in an African population: 1. Development and reproducibility. Public Health Nutr 2001;4:53-62.

33. Maclntyre UE, Venter CS, Vorster HH. A culture-sensitive quantitative food frequency questionnaire used in an African population: 2. Relative validation by 7-day weighed records and biomarkers. Public Health Nutr 2001;4:63-71.

34. Venter CS, Maclntyre UE, Vorster HH. The development and testing of a food portion photograph book for use in an African population. J Hum Nutr Diet 2000;13:205-18.

35. Pednekar MS, Gupta PC, Hebert JR, Hakama M. Joint effects of tobacco use and body mass on all-cause mortality in Mumbai, India: results from a populationbased cohort study. Am J Epidemiol 2008;167:330-40.

36. International Center for Alcohol Policies. International drinking guidelines. Washington, DC: International Center for Alcohol Policies, 2003. 12 p. (ICAP reports, 14)

37. Kruger HS, Venter CS, Steyn HS. A standardised physical activity questionnaire for a population in transition: the THUSA study. Afr J Phys Health Educ Recr Dance 2000;6:54-64.

38. Costa PT, Jr., McCrae RR. Revised NEO personality inventory (NEO-PI-R) professional manual. Odessa, FL: Psychological Assessment Resources, 1992. 101 p.

39. Adair LS, Kuzawa CW, Borja J. Maternal energy stores and diet composition during pregnancy program adolescent blood pressure. Circulation 2001;104:1034-9.

40. Forrester T. Historic and early life origins of hypertension in Africans. J Nutr 2004;134:211-6.

41. Cianfarani S, Germani D, Branca F. Low birthweight and adult insulin resistance: the "catch-up growth" hypothesis. Arch Dis Child Fetal Neonatal Ed 1999; 81:F71-3.

42. Neel JV. Diabetes mellitus: a "thrifty" genotype rendered detrimental by "progress"? Am J Hum Genet 1962;14:353-62.
43. Hales CN, Barker DJ. Type 2 (non-insulin-dependent) diabetes mellitus: the thrifty phenotype hypothesis. Diabetologia 1992;35:595-601.

44. Rankinen T, Zuberi A, Chagnon YC, Weisnagel SJ, Argyropoulos G, Walts B et al. The human obesity gene map: the 2005 update. Obesity (Silver Spring) 2006;14:529-644.

45. McDermott R. Ethics, epidemiology and the thrifty gene: biological determinism as a health hazard. Soc Sci Med 1998;47:1189-95.

46. Considine RV, Considine EL, Williams CJ, Nyce MR, Magosin SA, Bauer TL et al. Evidence against either a premature stop codon or the absence of obese gene mRNA in human obesity. J Clin Invest 1995;95:2986-8.

47. Considine RV, Sinha MK, Heiman ML, Kriauciunas A, Stephens TW, Nyce MR et al. Serum immunoreactiveleptin concentrations in normal-weight and obese humans. N Engl J Med 1996;334:292-5.

48. Bray GA, York DA. Clinical review 90: leptin and clinical medicine: a new piece in the puzzle of obesity. J Clin Endocrinol Metab 1997;82:2771-6.

49. Schwartz MW, Woods SC, Porte D Jr, Seeley RJ, Baskin DG. Central nervous system control of food intake. Nature 2000;404:661-71.

50. Casabiell X, Piñeiro V, Peino R, Lage M, Camiña J, Gallego R et al. Gender differences in both spontaneous and stimulated leptin secretion by human omental adipose tissue in vitro: dexamethasone and estradiol stimulate leptin release in women, but not in men. J Clin Endocrinol Metab 1998;83:2149-55.

51. Luukkaa V, Pesonen U, Huhtaniemi I, Lehtonen A, Tilvis R, Tuomilehto J et al. Inverse correlation between serum testosterone and leptin in men. J Clin Endocrinol Metab 1998;83:3243-6.

52. Sookoian S, Gemma C, García SI, Gianotti TF, Dieuzeide G, Roussos A et al. Short allele of serotonin transporter gene promoter is a risk factor for obesity in adolescents. Obesity (Silver Spring) 2007;15:271-6.

53. Verhagen M. Familiality, comorbidity and molecular genetic factors in major depressive disorder: the role of gender. Nijmegen: Ipskamp Drukkers, 2009. 205 p. (http://dare.ubn.kun.nl/dspace/bitstream/2066/74417/1/74417.pdf, accessed on 14 October 2009).

54. DiLalla LF, editor. Behaviour genetics principles: perspectives in development, personality and psychopathology. Washington, DC: American Psychological Association, 2004. 89 p. (Danish)

55. Chen YS, Torroni A, Excoffier L, Santachiara-Benerecetti AS, Wallace DC. Analysis of mtDNA variation in African populations reveals the most ancient of all human continent-specific haplogroups. Am J Hum Genet 1995;57:133-49. 